\title{
My Children, Your Children, Our Children, and My Well-Being: Life Satisfaction of "Empty Nest" Biological Parents and Stepparents
}

\author{
Katya Ivanova ${ }^{1}$ (D) \\ Published online: 12 March 2019 \\ (C) The Author(s) 2019
}

\begin{abstract}
Studies on the association between parenthood and subjective well-being (SWB) have largely ignored the growing population of adults who experience more complex types of parenthood such as stepparenthood and multipartner fertility. We utilize the 'Parents and Children in the Netherlands' survey (OKiN) to study the association between different parenting roles and life satisfaction, a key component of SWB. We focus on the adjustment of parents in later life, rather than at the moment when they are living with dependent (step)children. The analytical sample was 6130 empty nest parents with a partner $(10.9 \%$ reported having only stepchildren). The final linear regression models, accounted for individual selection into parenting status (e.g., educational attainment), characteristics of current partnership (e.g., trust in partner), and quality of intergenerational ties (i.e., average closeness with all (step)children). We find that once those variables were included in the models, no negative associations were found between any type of parenthood and life satisfaction. Interestingly, we find that quality of intergenerational ties acts as a suppressor; once accounted for, we find that (1) stepmothers report significantly and even substantially higher life satisfaction than mothers with only biological children with current partner; and (2) that fathers with only biological children from an ex-partner report higher life satisfaction than fathers with only biological children with current partner. Therefore, we argue that in order to better understand the predictive validity of type of parenthood for individual well-being, the quality of the intergenerational climate has to be considered.
\end{abstract}

Keywords Biological parent · Gender · Empty nest · Life satisfaction · Parenthood · Stepfather $\cdot$ Stepmother $\cdot$ Subjective well-being

Katya Ivanova

k.o.ivanova@uva.nl

1 Department of Sociology, University of Amsterdam, Nieuwe Achtergracht 166, Building REC B/C, 1018 WV Amsterdam, The Netherlands 


\section{Introduction}

Western societies have witnessed a growth in the instability of marriages and cohabitations over the past several decades, which has been combined with high rates of re-partnering (Amato and James 2010; Sweeney 2010; Thomson 2014). As the majority of relationship dissolutions involve couples with at least one minor child, this adult sequential monogamy has resulted in the proliferation of stepfamilies, as well as, upon the addition of new children to the higher order union-multipartner fertility (i.e., having biological children with more than one partner; Carlson and Furstenberg 2006; Lappegård and Rønsen 2013). Though ample literature exists on the repercussions of union instability for children and adults (e.g., Amato 2001; Bernardi et al. 2013; Gähler and Palmtag 2015), the interest in "reconstituted" households has primarily focused on the adjustment of the children raised in these partnerships. The somewhat consistent message has been that they fare worse off than children raised in intact households (Coleman et al. 2000). At the same time, the increased complexity in family experiences for children is unavoidably coupled with growth in the diversity of parenthood experiences. Though the majority of adults might still have only biological children with their current partners, a non-negligible group would have children with multiple partners and/or have (non-)resident stepchildren.

Although the importance of parenthood for subjective well-being (SWB) has been a mounting field of research, studies almost exclusively focus on the comparison of biological parents to non-parents, with somewhat mixed findings about which group does better on measures such as happiness and life satisfaction (e.g., Aassve et al. 2016; Balbo et al. 2013; Hank and Wagner 2013; Myrskylä and Margolis 2014). The repercussions of other, potentially more complex types of parenthood, have received substantially less attention despite the growing population of adults who experience these roles (Umberson et al. 2010). A considerable challenge for researchers have been the small sample sizes in the available larger family surveys. For example, a study on the association between parenthood and depression, using the US National Survey of Families and Households, was able to identify only 91 mothers who were living with stepchildren (in an original analytical sample of over 8000 parents) and that is without necessarily excluding women who were living with both step- and biological children (Evenson and Simon 2005). Another investigation into later life well-being and parenthood, using the Wisconsin Longitudinal Study of over 10,000 individuals, resulted with a subsample of only 9 stepparents without biological children in the analytical sample (Pudrovska 2009). In other words, our current understanding of the experience of stepparenthood, for example, is based on studies of concomitant parenting statuses (i.e., step and biological parent) which is problematic as the increase in the number of parenting roles which one performs (e.g., residential and nonresidential parent, biological and stepparent, etc.) can be linked to higher depressive symptomology (Shafer and Pace 2015). Additionally, a lot of what we currently know about the repercussions of parenting for adults, stems from studies on the gender differences in the challenges which these roles pose during the years when the parents are still living together with at least some of their children (e.g., Doodson and Davies 2014; Pace and Shafer 2015; Stewart 2005). Yet, assuming long term continuity in the documented early disadvantages in well-being among parents of children other than biological from current partner might be unwarranted, given studies which have shown that life events result in short-term fluctuations and eventual adaptation in individual well-being (Brickman and Campbell 1971; Clark 2018; Larsen 2000; Lykken and Tellegen 1996). This point has been rather prominent in longitudinal studies of individual well-being surrounding the transition 
to parenthood, where fluctuations are found around the time of childbirth, with eventual returns to before-child levels (e.g., Myrskylä and Margolis 2014).

The present contribution furthers our understanding of the significance of differing parenthood experiences for what is now a growing group in the population (i.e., parents of children other than biological with current partner). We use data from the 'Parents and Children in the Netherlands' survey (OKiN, Ouders en Kinderen in Nederland; Kalmijn et al. 2018), which is based on a systematic random oversample of adult-children who grew up in non-intact families. Both the grown-up children (25-45 years old at the time of the interview) and their biological and, if present, stepparents were surveyed about a range of family-related experiences and concurrent individual well-being. These data provide sufficient power to examine the association between specific types of parenthood (e.g., stepmother with no biological children) and adjustment, something which has been hardly achievable in previous works where concomitant parenting statuses were examined. A second important contribution of the present study is the attention to long term parental adjustment, focusing on the life satisfaction of empty-nest parents. As previously stated, a lot of what we know about the repercussions of family complexity for parental well-being is based on studies examining the period of ongoing parent-child coresidence. Yet, the question remains whether the early potential disadvantages in, for example, stepparental well-being have long-term scarring effects.

\section{Theoretical Background}

The limited earlier work on the adjustment of parents other than biological has rather consistently focused on stepfathers' and stepmothers' experiences and has suggested that the stepparent status is associated with lower well-being (e.g., Doodson and Davies 2014; Pace and Shafer 2015). It should be noted here that an exception to this pattern is a study by Pudrovska (2009) where later life adjustment was not found to be compromised by stepparenthood. Yet, that study utilized a sample of stepparents who also reported having own biological children, which makes drawing conclusions about what drives the effects somewhat challenging (i.e., are these stepparents doing well in later life because they also have own biological children).

Several mechanisms could underlie the negative association between individual wellbeing and more complex parenting roles. Foremost, we need to recognize that the relationship could exist because of selection into the different parenting statuses based on factors such as (but not limited to) socioeconomic status indicators. Various works have shown that there is a negative selection of individuals into the role of a stepparent (e.g., lower income earners, Carlson and Berger 2013; Hofferth and Anderson 2003), as well as, into the experience of multipartner fertility (e.g., Carlson and Furstenberg 2006). In other words, the population of stepparents and parents with multipartner fertility is hardly comparable to that of simple biological parents. In turn, the factors underlying the negative selection, such as lower individual income and lower educational attainment can be linked to worse subjective well-being (e.g., Yakovlev and Leguizamon 2012; for a review, see Diener and Biswas-Diener 2002). In other words, it is possible that the association between the more complex parenting statuses and maladjustment is driven by the negative selection of specific individuals into these more complicated parenting roles.

Over and above the possible selection described above, the maladjustment of some types of parents (e.g., stepparents, parents with multipartner fertility) could also be driven 
by partnership related factors. As has been frequently argued in the literature, reconstituted families are likely to face a number of challenges due to their lower institutionalization in society (Cherlin 1978, 2004). Not surprisingly, more complicated households, formed after the dissolution of at least one of the partners' previous unions, have been shown to be less stable than first, intact households (Lyngstad and Jalovaara 2010). Congruently, empirical work has shown that individuals in remarriages can report lower relationship quality than those in first unions (Skinner et al. 2002). As individuals' assessments of their current partnerships are a robust predictor of their subjective well-being (Dush and Amato 2005), it is then likely that the maladjustment of parents with more complex parenting roles could be driven by the fact that these individuals also have qualitatively different experiences of their partnerships in their reconstituted households. What should also be recognized here is since the experience of union instability is linked to worse individual adjustment (e.g., Amato 2000), any possible association between nonsimple biological parenthood (i.e., parenting children other than biological with current partner) and SWB might be driven by the life-course transitions which have led to that specific parenting status.

Finally, one of the most frequently cited mechanisms which could explain the maladjustment of parents with children other than biological from current partner, is the fact that the relational climate in reconstituted families tends to be a lot more complex than that in intact families, with numerous (intergenerational) ties having to be negotiated simultaneously (for a review, see Sweeney 2010). A number of studies have highlighted the challenges which negotiating multiple parenting roles pose not only for stepparents (e.g., Stewart 2007) but also for parents with biological children from multiple partners (Fomby 2018). This heightened parenting stress has in turn been related to measures of maladjustment such as depression (e.g., Shapiro and Stewart 2011). An argument can be made that this mechanism is most at play during the period when parents and (step)children are still living together and having to negotiate the diverse ties. Some authors have argued that once the initial period of forming a reconstituted family has passed, the stress associated with the lack of clear boundaries, rights, and obligations within these households, also subsides (Stewart 2005). In other words, given that the focus in the present study is on well-being in later life, it is possible to argue that the mere existence of multiple (intergenerational) ties does not necessarily lead to compromised (step)parental adjustment because the quality of these ties may not necessarily be substantially undermined. However, empirical work has argued that as the number of parent-child relationships increases and particularly in the presence of stepchildren, not only the quality of individual dyadic ties is negatively affected (e.g., worst or best parent-(step)child relationship) but also, the overall relational network (Ward et al. 2009). Similarly, even though stepkin increases the size of the network available to engage in intergenerational solidarity, researchers have found that the overall intergenerational transfers of both time and money in households with stepkin are lower than in the counterparts without stepkin (Wiemers et al. 2018). In other words, it appears that the first tumulus years of reconstructing the original household might, in fact, throw a long shadow as far as the overall relational climate in a nonintact family is concerned. Therefore, though focusing on later-life SWB among different parents, we still consider the role which the overall relational climate within the family might play. 


\section{The Present Study}

In this contribution, we utilize the Parents and Children in the Netherlands survey (OKiN, Ouders en Kinderen in Nederland; Kalmijn et al. 2018) to study the relationship between different parenting roles and life satisfaction, which is one of the key components of subjective well-being (Diener et al. 1999). We focus on the adjustment of parents in later life, rather than at the moment when they are still living with and potentially, caring for dependent (step)children. Given the available data, we are able to examine these associations for the various parenting roles separately, without facing the need to combine statuses as has been the case in previous works (e.g., a parent of step and biological children). In our work, we pay attention not only to the association between parental status and life satisfaction but also to what might be driving that possible relationship, by considering individual selection into the different parenting roles, the parent's partnership characteristics, and the overall quality of intergenerational ties in the family.

\section{Data and Method}

\subsection{Data}

In this paper, we utilized the "Parents and Children in the Netherlands" survey (OKiN, Ouders en Kinderen in Nederland; Kalmijn et al. 2018). The survey is based on a stratified random sample from the national registers of independently living adults, born in the Netherlands between 1971 and 1991 (aged 25-45). It contains a large oversample (75\%) of persons who grew up with separated and widowed parents, with an oversample of persons who grew up with a stepparent. These sampling strata were defined by the registered residence address of the primary respondents at age 15 and their biological parent(s) and possible new partners. Both the primary respondents (also referred to as anchors), as well as, their biological parents and these parents' current partners (designated alters) were independently approached for participation, with response rates of respectively $62 \%(N=6232)$ and $38 \%(N=9325)$. The response rate for the anchors is considerably higher that other large-scale Dutch surveys (de Leeuw and de Heer 2002), whereas the lower response of the parents is due to the absence of a face-to-face interview (see Kalmijn et al. 2018 for further information). Given the current study's focus on the life satisfaction of different types of parents in later life, we utilized the alter data (i.e., the parent figures of the 25-45-year-old anchors). Due to the oversampling strategy, the number of stepparents in the OKiN survey is notably higher than in many other frequently used data sources.

The alter fieldwork started with a letter with an invitation to participate in a Computer Assisted Web Interview survey (CAWI). Respondents who participated could automatically be part of a lottery for iPads. A brochure was included in the letter which mentioned the possibility of linking information from children (the anchors) to the parents for statistical purposes and emphasized the voluntary nature of the survey. By design, both partners in an alter household received a letter (e.g., the two biological parents of an anchor or one biological parent and his/her new partner). That means that some of the participating alters in the survey are clustered within households. The partners received individual letters with their own codes. One week later, nonrespondents received a reminder to participate in the CAWI survey. Two weeks later, nonrespondents received another reminder, this time with 
a paper-version of the CAWI questionnaire included (PAPI). Respondents were offered the choice of modes in this letter (CAWI or PAPI). Three weeks after the initial approach, nonrespondents received a final reminder and a PAPI version of the questionnaire. For further information about the survey design, fieldwork, and response, please see the work of Kalmijn et al. (2018).

\subsection{Selectivity Analyses of Alter Data}

The somewhat lower response rate among the parent figures of the OKiN anchors (i.e., $38 \%$ ), could raise questions about the possible selectivity in the available sample of parent figures. Therefore, we performed a number of checks to assess the selectivity in the alter sample. As the data were collected with the assistance of Statistics Netherlands, additional register-based information was available in OKiN about both the participating, as well as, the non-participating alters. For each participating anchor (i.e., the adult-child), we identified whether he or she had a specific parent figure alive (biological father and mother, as well as, their potential current coresident partners) and if they existed, whether these parent figures participated in the alter data collection. We used register information about a number of individual characteristics (e.g., current marital status, income, age, ethnic-minority status) to predict whether the alter participated in the survey, provided that he/she was present in the population as a whole. Additionally, we utilized information provided by the anchor about the alter's health and the level of closeness between anchor and alter to predict alter's participation. The results of these logistic analyses can be found in "Appendix". As can be seen in that table, some selectivity can be observed in the sample of OKiN alter participants. For example, participating alters were more likely to be older, of native Dutch origin, financially well-off, and in good health. Also, odds of participation were higher for alters whose relationship with the participating anchor was closer. At the same time, we see that for each point increase on the scale of (step)parent-child closeness, the odds of that parent figure participating increase by only about 8 percent. In other words, though the participating alters might have a better relationship on average with the anchor than non-participating alters, this intergenerational tie quality is not a very strong predictor of response. Finally, men (biological fathers, as well as, stepfather figures) were less likely to participate than biological mothers. However, what is important for the present study, is that when we tested the interactions between the predictors depicted in "Appendix" and "type of parent" (within gender-i.e., stepmother vs biological mother and stepfather vs biological father), we did not find that the selectivity was more or less pronounced for some parents than others (results available upon request). The only exceptions were (a) that stepmothers whose current marital status was "divorced" were less likely to participate whereas currently divorced biological mothers were more likely to participate, and (b) that non-ethnically Dutch biological mothers were less likely to participate whereas that was not the case for stepmothers. In summary, our comparisons between different types of parents should not be compromised by, for example, financially better off stepparents and worse off biological parents participating in the survey.

\subsection{Analytical Sample}

Of the original 9325 parent figures which participated in the OKiN alter data collection, 255 did not report having any children and were thus, excluded from the analytical sample. Furthermore, we excluded parents (1) who reported that they were currently living 
together with any of their children ( $n=1295$ of those for whom parenting status could be determined); and (2) who either reported not having a partner currently or skipped this question ( $n=1865$ of those for whom parenting status could be determined). The first decision was made in order to avoid the possible issue that coresidence with children could be related to both parent type and life satisfaction whereas the second was driven by the fact that stepparenthood was anchored on currently having a partner (i.e., "Does your partner have children from a previous relationship?). In other words, stepparents always had a current partner, whereas that was not always the case for parents with only biological children. The final analytical sample was 6130 empty nest parents with a partner. Of these parents, $10.8 \%$ reported having only stepchildren and $43.0 \%$ reported having step and biological children. These were sufficiently large sample sizes of stepfathers and stepmothers in order to make a number of theoretically important distinctions in people's stepparenthood experiences which have not been possible in previous studies of stepparents' well-being. Of the participating alters, 4178 were clustered into households (i.e., both partners in a household participated in the data collection). When applicable (i.e., in the analyses not split by gender of the parents), we corrected for this clustering of respondents in households.

\subsection{Measures}

\subsubsection{Life Satisfaction}

The dependent variable in this study was measured using three items from the short Satisfaction with Life Scale of Diener et al. (1985) and Pavot and Diener (2009). The participants rated on a scale from $1=$ completely agree to $5=$ completely disagree the following statements: "My life is ideal in most respects", "The conditions of my life are excellent", and "All in all, I am satisfied with my life". The scale was created based on the mean of the three recoded items $\left(M=3.98, S D=0.67 ; M_{\text {fathers }}=3.97, S D_{\text {fathers }}=0.66 ; M_{\text {mothers }}=3.98\right.$, $S D_{\text {mothers }}=0.69$ ) and the reliability of the scale was $\alpha=.86$. Further descriptive information about the scale is provided in Table 1.

\subsubsection{Parenthood Role}

The parenthood role of the participants was determined by the type of children that they reported having. Each alter was asked whether she/he (1) has biological children with the current partner; (2) has biological children with an ex-partner, and (3) is with a partner who has children from a previous relationship. Subsequently, for each subset of children, the alter was asked whether (a) he/she is currently living with and (b) has ever lived with these children. We would like to remind the reader that we excluded participants who currently lived with any children from the analytical sample. Based on the types of children and their residential history, we created six groups of parents: (1) parent with only biological children from current partner $(n=1871)$; (2) parent with only biological children from an ex-partner $(n=701)$; (3) parent with only biological children from multiple partners $(n=256)$; (4) parent with only stepchildren, no history of shared residence $(n=247)$; (5) parent with only stepchildren, with history of shared residence $(n=418)$; and finally $(6)$ parent of both biological and stepchildren $(n=2637)$. 


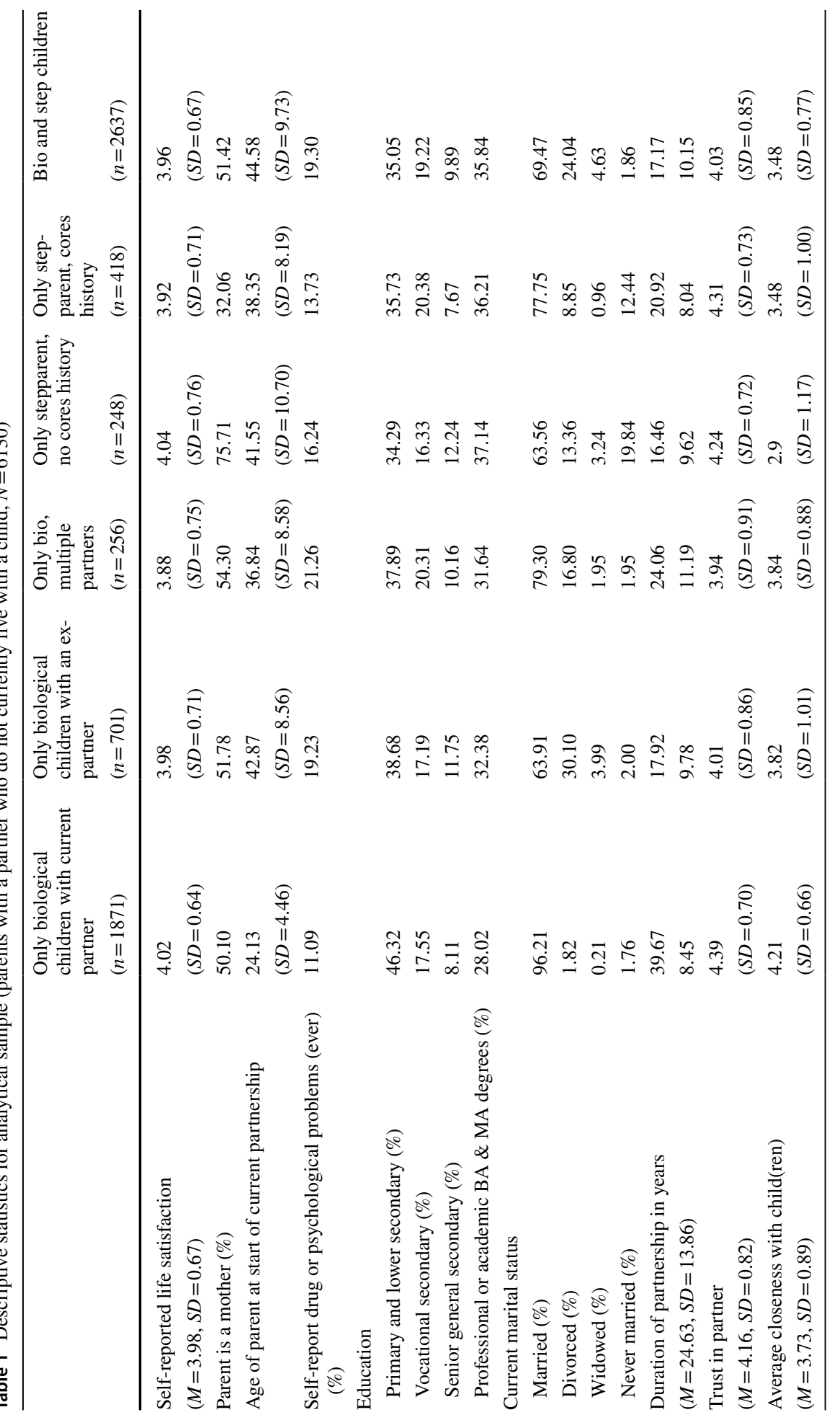




\subsubsection{Individual Characteristics}

In order to account for the possible selection into the different parenthood roles, we took into consideration the following individual characteristics: (1) age at start of current partnership; (2) gender; (3) highest educational attainment, split into four categories (primary and lower secondary, vocational secondary, senior general secondary, and professional or academic bachelor and master degree); and (4) self-reported mental and addiction problems over the life course. These problems were assessed using the question, "Have you ever needed help for addiction or mental health problems?" $(1=$ no, $2=y e s$, for addiction, $3=y e s$, for mental health problems, and $4=y e s$, for both). As the majority of our analytical sample reported not having needed help (83.6\%), we combined the rest of the responses into one category. Descriptive information per type of parent is provided in Table 1 . We could also account for the current yearly household income of the respondents, as well as, the primary source of individual income. However, given that those were only assessed at the time of the interview and thus, could not necessarily account for selection into parenting status, we chose not to utilize them in our models.

\subsubsection{Partnership History and Current Partnership Characteristics}

As outlined in the front end of the manuscript, the association between parental role and life satisfaction might be driven by the fact that stepparents and parents with a mix of children in particular, might have a more complicated partnership history or lower quality current partnership. Therefore, we took into consideration the participants' current marital status as recorded in the Dutch register data $(1=$ married, $2=$ divorced, $3=$ widowed, and $4=$ never married). It is important to note here that the current marital status is not necessarily linked to the current partnership. In other words, though all participants in our analytical sample had a partner, $16.2 \%$ of our sample had a marital status of "divorced", $2.8 \%$ "widowed", and 3.3\% "never married". In other words, for the first two of the abovementioned groups, the current partnership was certainly a higher-order union. We recognize that though the majority of the sample was married at the time of the data collection, this did not mean that this was the alter's first marriage. However, we were unable to control for which order marriage the current union was because the participants were only asked for details about earlier partnerships if they resulted in childbearing (i.e., if the alter was married before but did not have children, we did not have information about the experience of that union). Therefore, the register data about current marital status were our best source of information about partnership history (for example, via the category "divorced" though currently with a partner).

With respect to the characteristics of the current partnership, we accounted for its duration in years, as well as, for the participant's self-reported trust in their partner ("I find it difficult to trust my partner", $1=$ fully agree to $5=$ fully disagree ). Though this single item is not an explicit measure of the quality of the current partnership, this was the best measure we had available in the data. Furthermore, the item was significantly correlated both with the duration of the union $(r=.19, p<.01)$, as well as, with life satisfaction $(r=.24, p<.01)$, which gave us confidence that it is an apt proxy for the subjective experience of the current partnership. Further descriptive information about these variables is provided in Table 1. 


\subsubsection{Overall Quality of Intergenerational Ties}

As stated in the theoretical section, parents with a mix of different children might report lower well-being because of the more tumulus relationships that they have with their (step) children. In the OKiN data, whenever alters reported having a certain type of children (e.g., biological children with current partner), they were asked how close they were with up to two children from that subset. ${ }^{1}$ The answer categories ranged from $1=$ very close to $5=$ not close at all. The items were recoded so that a higher value denoted closer relationship. We then took the average of all reported relationships in order to capture the overall "relational climate" that parents experienced with all of their biological (and potential step-) children. Table 1 displays further descriptive information about this variable.

\subsection{Analytical Strategy}

In addition to presenting basic descriptive statistics by parenthood group of interest, we run a number of multivariable linear regression models, with self-reported life satisfaction as the dependent variable. When the full sample of alters is used, we account for the fact that we might have multiple alters from the same households, by clustering the standard errors within a household indicator. We estimate four consecutive models: Model 1 (baseline parenthood differences), Model 2 (adding selection), Model 3 (adding partnership), and Model 4 (adding average level of intergenerational closeness). We display the corresponding BIC statistic and adjusted $R^{2}$ in order to judge the model fit. In all analyses, we pay explicit attention not only to the statistical significance of our findings but also to the magnitude of the potential gaps between groups by discussing the results in terms of differences in standard deviations.

\section{Results}

We begin our presentation of the results with a reflection on some basic descriptive statistics. Foremost, it is interesting to point out that the mean differences in self-reported life satisfaction between the groups of parents were not substantial, with the group of parents with only stepchildren (no history of coresidence), actually at par with parents of only biological children from current partner (see Table 1). Compared to this latter group of parents, three groups reported significantly though not substantially lower mean levels of life satisfaction: those with multipartner fertility, stepparents with coresidential history, and parents of both biological and stepchildren. Further analyses showed that a gender difference within the groups was only present for the group of stepparents with coresidential history with children. In that group, stepmothers reported significantly higher life satisfaction than stepfathers $\left(M_{\text {stepfathers }}=3.86, S D=0.72, M_{\text {stepmothers }}=4.05, S D=0.67, t(415)=2.60\right.$, $p<0.05)$.

\footnotetext{
1 Important to note here is that there were very few parents who reported having a particular type of children but then reported on the closeness with none or only one of them (when they reported having more than one). For example, of the 3281 parents who reported having (a) stepchild(ren), only $1.9 \%$ did not report on the closeness with any stepchild. The key issue here is that we did not know whether the closeness is not reported because the child is no longer alive. Therefore, we chose not to impute the few missing closeness values.
} 
In terms of the potential differences between the groups in the variables which might result in variations in individual life satisfaction, we saw that those who were parents to only biological children with current partner were more likely to be currently married than the other parent groups and to have been with their partner the longest. Interestingly, in terms of educational attainment, there were fewer parents with only biological children from current partner who had professional or academic degrees than in the other parent groups. However, the percentage of parents reporting having sought help for addiction or psychological problems was lowest in the group of parents of only biological children with current partner. They also reported higher average quality of closeness with their children (see Table 1).

We would now like to turn to the multiple linear regression models displayed in Tables 2 (baseline parenthood differences), 3 (selection), 4 (partnership), and 5 (average level of intergenerational closeness). In all tables and models, parents of only biological children with current partner are the reference category. Whereas the tables present the unstandardized regression coefficients, we also pay attention to the magnitude of the statistically significant results by discussing differences in terms of standard deviations of life satisfaction (i.e., coefficient $/ S D$ of life satisfaction). If we look at Model 1, Table 2, we see that when controlled only for the gender of the respondent, parents with more complicated parenting roles reported lower life satisfaction than the reference category, with two exceptions-parents with biological children with an ex-partner and stepparents without history of coresidence, who did not differ from the reference category. The gaps between the groups are not always substantial, ranging from .21 of a standard deviation in life satisfaction (for 'only biological parent with multiple partners', $-0.14 / 0.67$ ) to .10 of a standard deviation (for 'biological and stepparent', -0.07/0.67). Model 2, however, shows that these differences might be gender specific. In fact, the lower life satisfaction among parents with complex parenting roles, appeared to be more pronounced for fathers than mothers. For example, whereas stepfathers, with coresidential history, report about a quarter of a standard deviation lower life satisfaction $(-0.16 / 0.67)$ than fathers of only biological children with current partner, comparable stepmothers actually report slightly higher (though not statistically significant) life satisfaction than the reference category. In light of these models and the fact that (step)parenthood is a highly gendered experience (Fine 1986), the rest of the models were estimated separately for fathers and mothers.

Table 3 shows the association between the specified parenting roles and life satisfaction, controlling for differences in the individual characteristics of the various parents. For both fathers and mothers, not having sought help for addiction/mental health problems, as well as, higher educational attainment were positively associated with life satisfaction. After controlling for these factors, we see that the negative association between a more complex parenting role and individual well-being was still present for stepfathers with history of coresidence, as well as, for mothers with biological children from an ex-partner and mothers of biological and stepchildren. Stepfathers who had lived with their stepchildren report about a fifth of a standard deviation lower life satisfaction than men with only biological children from the current partner $(-0.14 / 0.66)$; the magnitude of the difference is comparable for mothers with biological children with an ex $(-0.14 / 0.69)$ and mothers of both biological and stepchildren $(-0.13 / 0.69)$.

Table 4 displays the results from the linear regression, estimating the differences between the various parents in their life satisfaction once selection at the individual level and current partnership characteristics were accounted for. For both men and women, trust in the current partner was positively associated with well-being, with a one-point increase in trust linked to a boost of .27 of a standard deviation for fathers $(0.18 / 0.66)$ and .25 for 


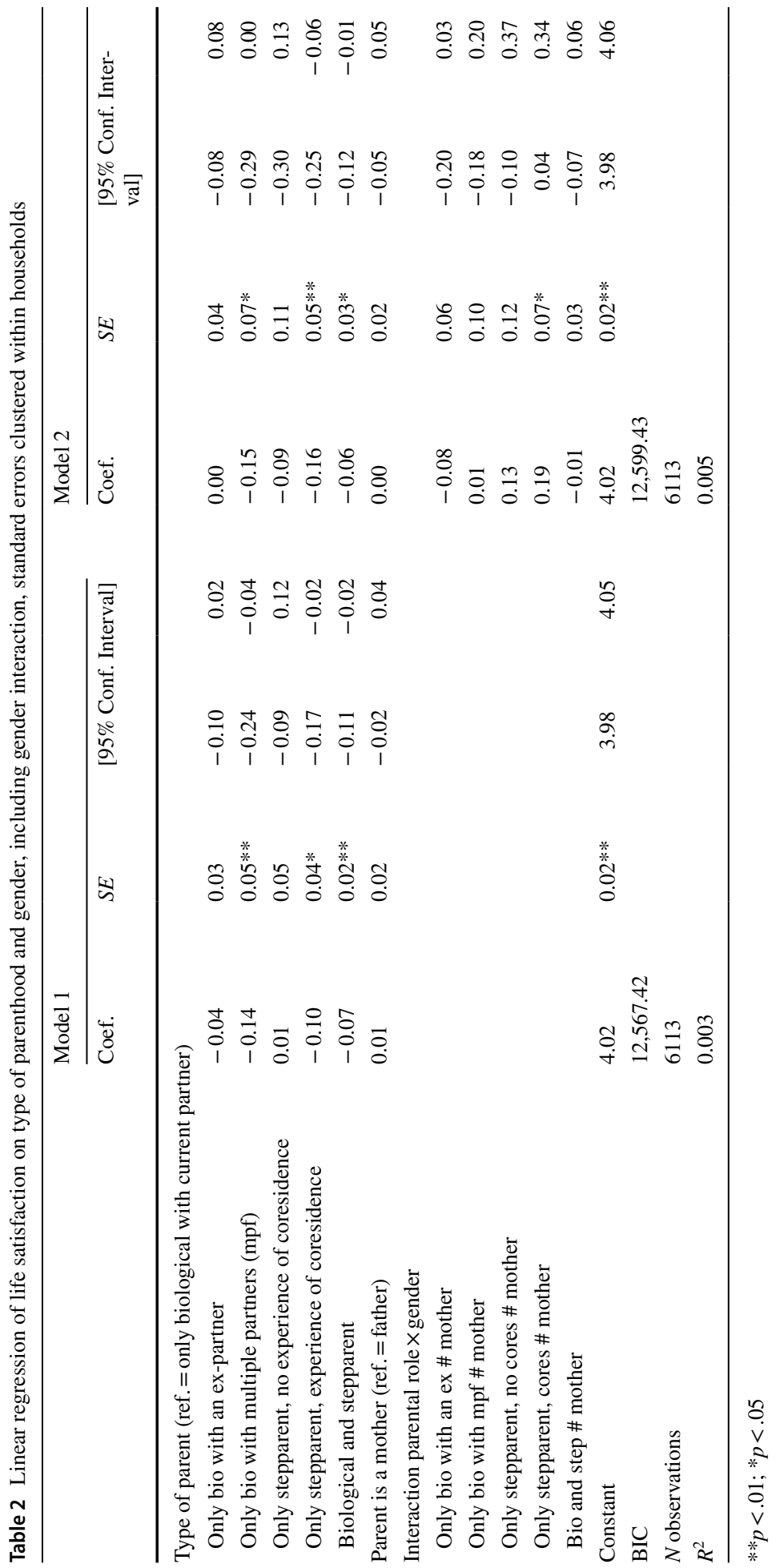




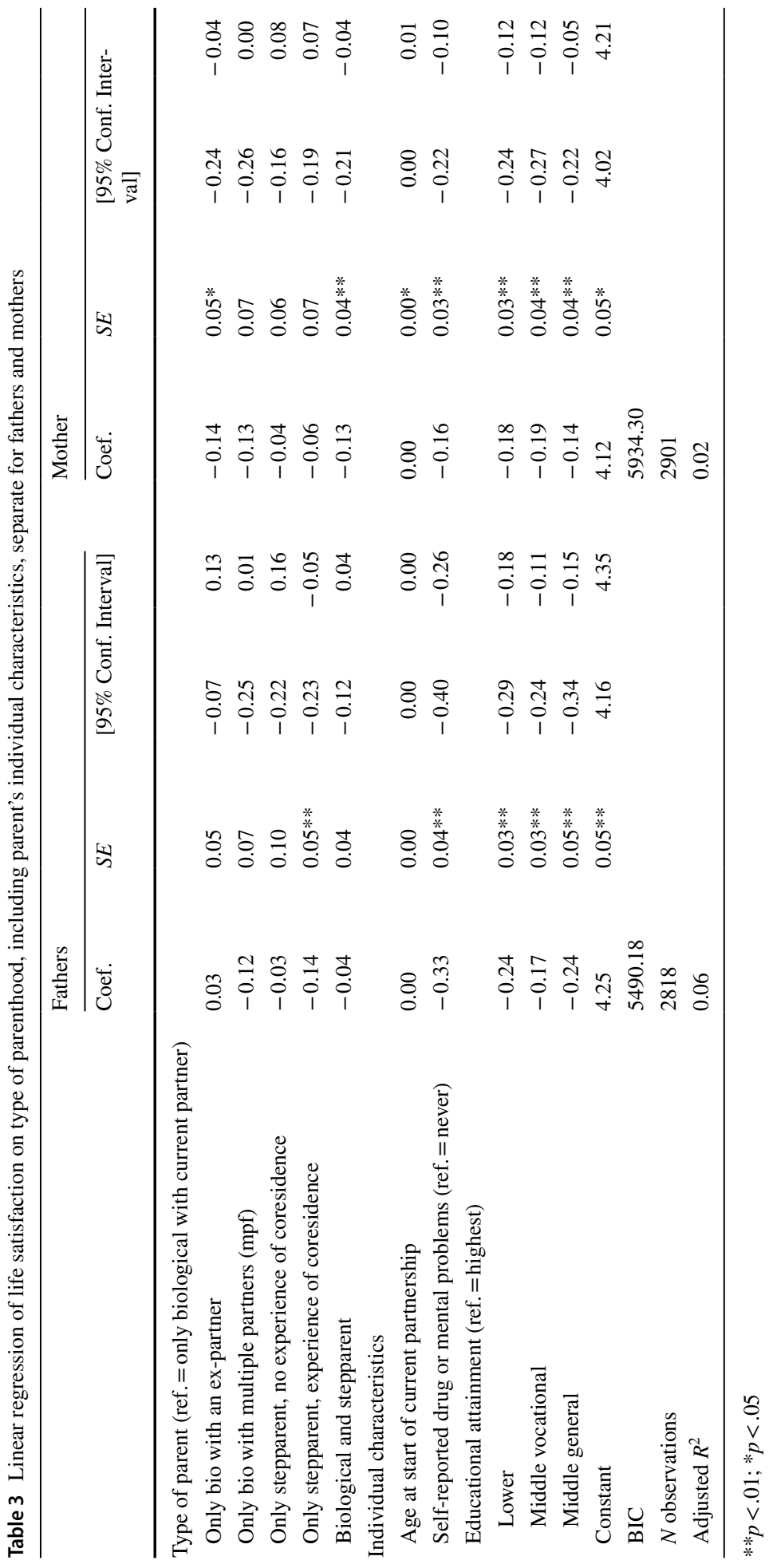




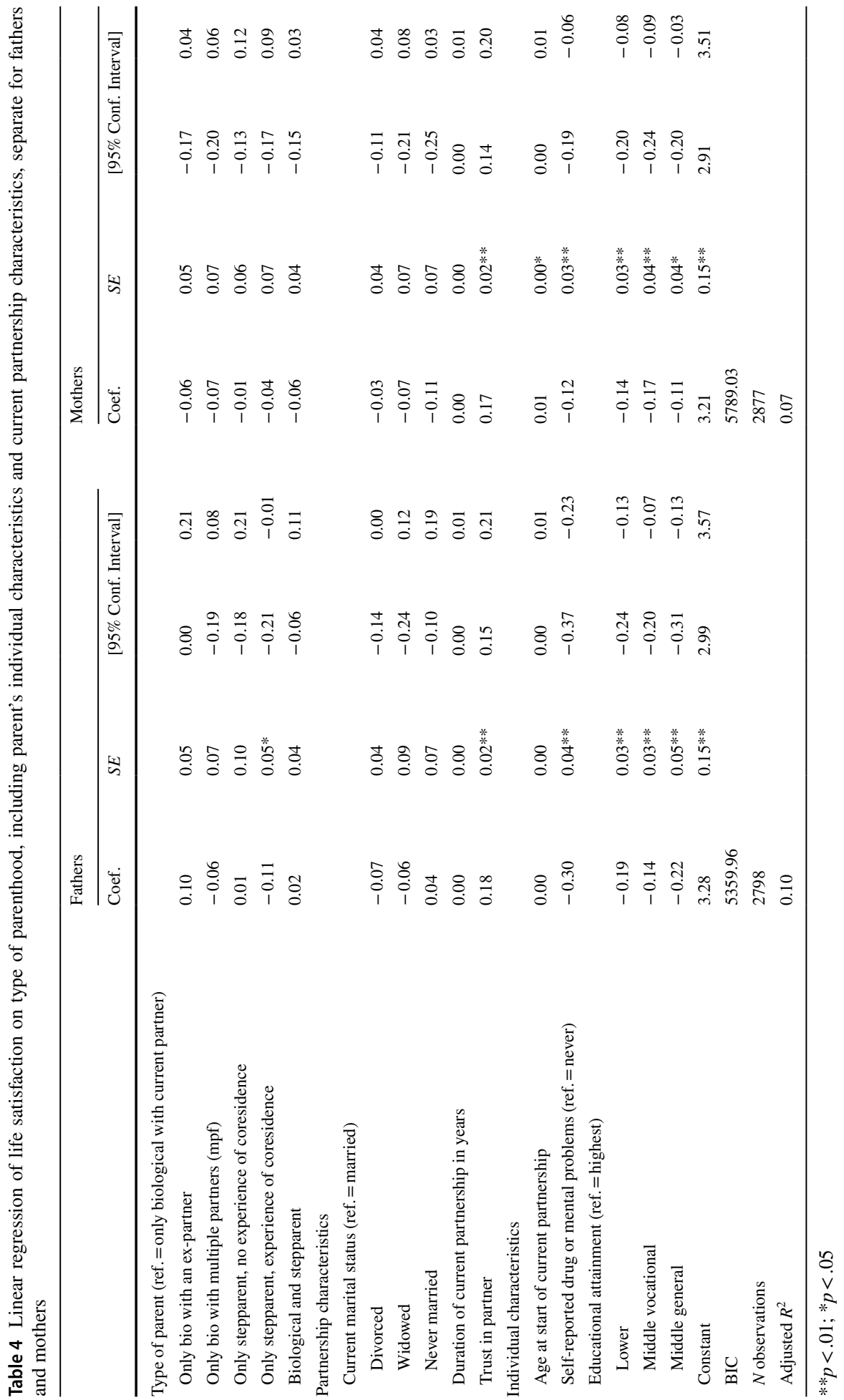


mothers (0.17/0.69). At this point, the only statistically significant difference in SWB which remained was for the stepfathers with the history of coresidence (no differences remaining for the mothers). Those men still reported significantly lower life-satisfaction.

Our final model accounted for the self-reported quality of parents' intergenerational ties. The results are displayed in Table 5 and unsurprisingly, an increase in the average closeness with children was linked to higher life satisfaction for both fathers and mothers. In these models, stepfathers with history of coresidence no longer differed from the reference category in their self-reported life satisfaction. What is more important is that accounting for the quality of intergenerational ties resulted in the surfacing of two interesting statistically significant associations. For fathers who had biological children only with an expartner and for stepmothers, without history of coresidence, the average closeness with children was not acting as a mediator in the association between parenting role and life satisfaction but rather, as a suppressor variable. In other words, accounting for the association between average closeness with children and life satisfaction, allowed us to reveal the true association between these parenting roles and parents' well-being. Table 5 shows that non-resident stepmothers reported significantly higher life satisfaction than the reference group. In fact, the difference was about a third of a standard deviation $(0.22 / 0.69)$ which is not an unsubstantial advantage. The gap was much smaller for fathers of biological children with an ex, who reported about a fifth of a standard deviation higher life-satisfaction than the reference category $(0.14 / 0.66)$. The final models showed improvement in fit compared to the previously estimated models, as demonstrated by the lower BIC statistic and the improved adjuster $R^{2}$ statistic.

\section{Discussion}

In this contribution, we examined the association between various types of parenthood and life satisfaction of empty nest, partnered parents. Though the link between individual adjustment and childbearing has been a booming line of research (e.g., Aassve et al. 2016; Balbo et al. 2013; Hank and Wagner 2013; Myrskylä and Margolis 2014), the attention has thus far, focused almost exclusively on the experience of biological parenthood. The limited research into the welfare of other types of parents has mostly suggested that deficiencies in parents' adjustment is to be expected during the earlier stages of family restructuring, but that the stress associated with parenting nonbiological children might be attenuated with the passage of time (Stewart 2005). Unfortunately, currently available data have hardly allowed researchers to truly examine non-overlapping parenthood statuses (e.g., a stepmother who does not also have biological children), which has meant that the understanding of what drives the potential differences between types of parents, such as number of parenting roles or a particular parenting role, has been limited. In this contribution, we were able to examine the association between specific parenthood statuses and parents' life satisfaction. In addition to highlighting possible differences between distinct groups of parents in their subjective well-being (SWB) in later life, we also paid attention to the possible mechanisms which might drive the studied association. Three noteworthy points emerged from our analyses.

The first point concerns the issue of selection. We found that many of the differences between our reference group of parents (those with least complicated parenting histories) and the other types of parents, were largely non-existent once we accounted for a number of individual and partnership level characteristics. This result resonates with a number of 


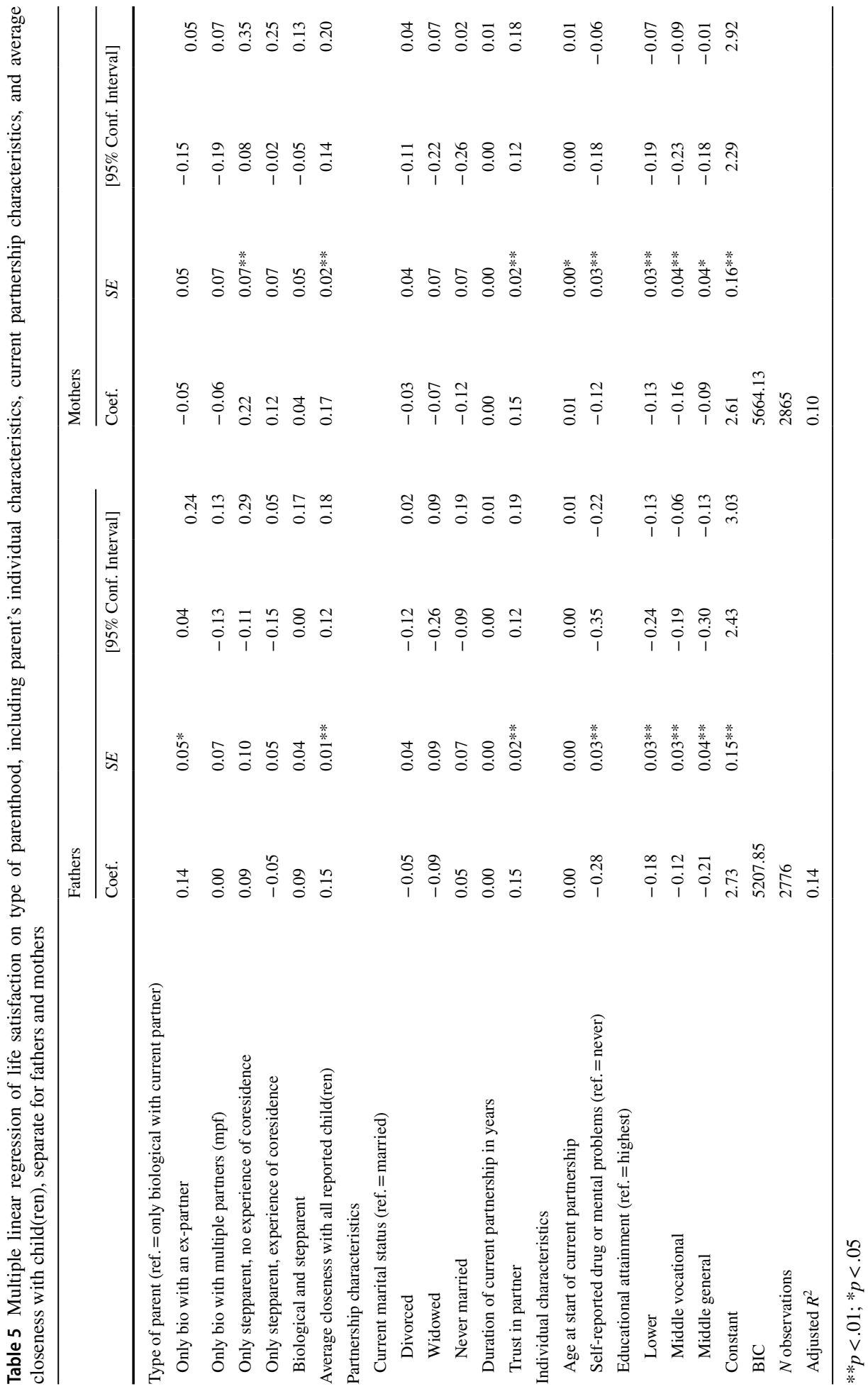


previous conclusions in the literature. For example, the negative selection of individuals into specific partnership statuses and parent roles, rather than the experiences themselves, has been an often evoked mechanism why these individuals might be disadvantaged on a number of outcomes (Evenhouse and Reilly 2004; Gratz 2017; Hofferth and Anderson 2003). What is important to note here, is that we were able to account only for a few individual characteristics when addressing selection and some of those were even captured in a way which did not necessarily ensure that they preceded the selection into parenting role. Unquestionably, a more robust test of the selection mechanism would require the use of longitudinal data, with high enough number of individuals experiencing the entry into a complex parenting role. Such future endeavors would also benefit from considering how baseline levels of SWB and a more diverse set of individual characteristics (e.g., personality; Roberts et al. 2007) could in fact drive the selection into specific parenting statuses. At this point, though we are able to disentangle very concrete parenting experiences from each other, our work remains largely descriptive, rather than implying clear evidence of causal links.

Another important finding in our work is that the mean level of midlife SWB of parents who had children other than biological with current partner did not differ substantially from the least complex group of parents (only biological children from current partner). Though some of the contrasts were statistically significant, their magnitude was not particularly striking. This is in line with the previously stated proposition that the experience of heightened stress associated with more complex types of parenthood, and stepparenthood in particular, might be matter of adjustment to the less clear boundaries within a reconstituted family (Stewart 2005). Some earlier empirical work has in fact, shown that having a stepchild is not associated with depressive symptomology in late midlife and early old age, though in those studies, the stepparenthood status was not necessarily decoupled from concurrent biological parenthood (Pudrovska 2009). What we did see, however, is that when compromised mean level life satisfaction could be found, that was specifically the case for fathers, rather than mothers. This might be surprising in light of qualitative studies pointing to stepmothers' difficulties in particular, with performing the role of a mother while not being a 'real' mother (Doodson 2014; Sanner and Coleman 2017; Weaver and Coleman 2005, 2010). We address this finding in the subsequent paragraphs.

The final point that we would like to discuss concerns the substantially higher life satisfaction of nonresident stepmothers and fathers of children with an ex-partner compared to biological parents of children with the current partner. Our results suggest that once we account for the overall quality of intergenerational ties, these two more 'complex' groups of parents report substantially higher life satisfaction than the reference group. It is interesting to point out that previous studies which have shown worse adjustment among non-simple biological parents, do not account for the quality of intergenerational ties (e.g., Shafer and Pace 2015; Shapiro and Stewart 2011) whereas the longitudinal study of Pudrovska (2009), which showed no differences between middleaged step- and biological parents in depressive symptomology, did account for closeness between parents and children. ${ }^{2}$ The 'advantage' in terms of SWB was particularly pronounced for the nonresident stepmothers where it amounted to a third of a standard deviation. A more rigorous examination of this finding would require further attention to possible positive selection into these two parenting roles, based on individual level

\footnotetext{
${ }^{2}$ It is important to point out here that the samples in these studies, as well as, the precise parenthood configurations are rather distinct and the findings may thus, not lend themselves easily to direct comparisons.
} 
characteristics, which we did not capture in this study. For example, given the primacy of women in kinkeeping (Di Leonardo 1987; Hagestad 1986; Kalmijn 2007; Rosenthal 1985), it is possible that the selection into the role of a stepmother is driven by factors such as interpersonal skills which we have not addressed in this contribution and which remain an avenue for further investigations into the selection of individuals into diverse parenthood statuses.

Another question which the stepmother finding raises, is whether it is driven by the non-biological parenthood status in particular (i.e., the experiences of nonresident stepmothers might resemble those of women without children quite closely), or rather, by the fact that these women do in the end have children, though not biological ones. As our sample of respondents were all parents, we cannot examine if nonresident stepmothers report similar levels of life satisfaction as non-mothers. Given our findings, we argue that it is possible that stepmothers draw benefits from having stepchildren precisely because in our sample these women do not have other children. In other words, despite the absense of biological children in their network, these women still have some ties (which they may not have expected) with a younger generation via their stepchildren. We acknowledge, however, that these are post hoc interpretations of the findings. The study of non-biological mothers' experiences remains a somewhat underdeveloped line of research, which requires not only high quality survey data, with large enough samples of these women, but also potentially, further in-depth qualitative work to help uncover the underlying mechanisms.

Despite the potential contributions of this work, we would like to acknowledge some caveats which provide opportunities for further research. Foremost, we do not examine changes in subjective well-being as a result of changes in parental status. As discussed above, our results may be a reflection of selection into these states, rather than a causal change per se. Understanding whether, for example, stepmothers experience a true boost in their life satisfaction when stepchildren are added to their networks, would require following these women over time. In our work, we have made an effort not to imply that we find any evidence of causal associations. We also need to recognize that we are only observing "surviving" partnerships. For example, though the unions of simple nonresident stepparents were the shortest, their average length was still well over a decade. In other words, we are missing those individuals who at some point in their lives, performed the role of a resident or nonresident stepparent, but who are currently separated from the biological parent of the children and whose SWB might be significantly lower than that of single simple biological parents. Unfortunately, given that the alter sample frame in OKiN was based on recruiting the anchors' biological parents and their current partners, we did not have information on non-partnered non-biological parents. Therefore, it is important to realize that our findings can only potentially be generalized to the population of currently partnered parents.

In summary, what we have tried to highlight in this work is that the experience of more complex types of parenthood is rather heterogeneous, with diverse constellations of (step)children which can have distinct potential repercussions for the mothers' and fathers' long-term subjective well-being. We need to recognize that the increase in family complexity, experienced over the past decades in most Western countries, has had important repercussions not only for the children involved but also, for the adults who have had to perform increasingly complex parenting roles. At the same time, this manuscript also highlights the long term resiliance of those who manage to navigate the initial, possibly volatile restructuring of the family system. 
Acknowledgements The study was conducted in the context of a larger project on Family Complexity which was funded by an ERC grant of the European Commission in the Horizon 2020 program (ERC Advanced Grant No. 669334). Please see www.familycomplexity.eu for more information on this project.

Open Access This article is distributed under the terms of the Creative Commons Attribution 4.0 International License (http://creativecommons.org/licenses/by/4.0/), which permits unrestricted use, distribution, and reproduction in any medium, provided you give appropriate credit to the original author(s) and the source, provide a link to the Creative Commons license, and indicate if changes were made.

\section{Appendix}

See Table 6.

Table 6 Results from logistic regression analysis predicting alter participation in survey

\begin{tabular}{|c|c|c|c|c|c|}
\hline & Coef. & $S E$ & \multicolumn{2}{|c|}{$[95 \% C I]$} & $O R$ \\
\hline \multicolumn{6}{|l|}{ Type of parent (ref. biological mother) } \\
\hline Biological father & -0.41 & $0.05^{* *}$ & -0.51 & -0.32 & 0.66 \\
\hline Partner of biological mother & -0.55 & $0.06^{* *}$ & -0.67 & -0.43 & 0.58 \\
\hline Partner of biological father & -0.11 & 0.07 & -0.24 & 0.03 & 0.90 \\
\hline \multicolumn{6}{|l|}{ Current marital status (ref. married) } \\
\hline Divorced & 0.01 & 0.05 & -0.08 & 0.10 & 1.01 \\
\hline Widowed & -0.01 & 0.08 & -0.15 & 0.14 & .99 \\
\hline Never married & -0.01 & 0.09 & -0.19 & 0.18 & .99 \\
\hline Current age & 0.03 & $0.00 * *$ & 0.03 & 0.04 & 1.04 \\
\hline \multicolumn{6}{|l|}{ Origin (ref. native Dutch) } \\
\hline Western foreign & -0.65 & $0.10 * *$ & -0.85 & -0.45 & 0.52 \\
\hline Non-western foreign & -0.23 & $0.07 * *$ & -0.36 & -0.10 & 0.79 \\
\hline \multicolumn{6}{|l|}{ Individual income (ref. 3rd quintile) } \\
\hline 1st quintile & -0.32 & $0.07 * *$ & -0.47 & -0.18 & 0.72 \\
\hline 2nd quintile & -0.18 & $0.06 * *$ & -0.30 & -0.06 & 0.83 \\
\hline 4th quintile & 0.18 & $0.06 * *$ & 0.07 & 0.29 & 1.19 \\
\hline 5th quintile & 0.44 & $0.06 * *$ & 0.33 & 0.56 & 1.56 \\
\hline \multicolumn{6}{|l|}{ Place of living (ref. moderately urbanized) } \\
\hline Very strongly urbanized & 0.19 & $0.07 * *$ & 0.06 & 0.32 & 1.21 \\
\hline Strongly urbanized & 0.06 & 0.05 & -0.05 & 0.16 & 1.06 \\
\hline Hardly urbanized & 0.00 & 0.06 & -0.12 & 0.11 & 1.00 \\
\hline Not urbanized & -0.04 & 0.07 & -0.18 & 0.10 & 0.96 \\
\hline \multicolumn{6}{|l|}{ Housing (ref. owns home) } \\
\hline Rent, with housing benefits & -0.54 & $0.07 * *$ & -0.68 & -0.40 & 0.58 \\
\hline Rent, no housing benefits & -0.34 & $0.05^{* *}$ & -0.44 & -0.24 & 0.71 \\
\hline Lives in poverty-problem-accumulation area $($ ref. $=$ no) & -0.12 & $0.06^{*}$ & -0.23 & 0.00 & 0.89 \\
\hline $\begin{array}{l}\text { Anchor reports alter is in (very) good health (ref. = mod- } \\
\text { erate/(very) bad) }\end{array}$ & 0.23 & $0.04 * *$ & 0.16 & 0.31 & 1.26 \\
\hline Anchor reported level of closeness with alter & 0.08 & $0.02 * *$ & 0.05 & 0.12 & 1.08 \\
\hline Constant & -2.46 & $0.20 * *$ & -2.85 & -2.07 & 0.09 \\
\hline
\end{tabular}

$* * p<.01 ; * p<.05$ 


\section{References}

Aassve, A., Arpino, B., \& Balbo, N. (2016). It takes two to tango: Couples' happiness and childbearing. European Journal of Population, 32, 339-354.

Amato, P. R. (2000). The consequences of divorce for adults and children. Journal of Marriage and Family, 62, 1269-1287.

Amato, P. R. (2001). Children of divorce in the 1990s: An update of the Amato \& Keith (1991) meta-analysis. Journal of Family Psychology, 15, 355-370.

Amato, P. R., \& James, S. (2010). Divorce in Europe and the United States: Commonalities and differences across nations. Family Science, 1, 2-13.

Balbo, N., Billari, F. C., \& Mills, M. (2013). Fertility in advanced societies: A review of research. European Journal of Population/Revue Européenne de Démographie, 29, 1-38.

Bernardi, F., Härkönen, J., Boertien, D., Andersson Rydell, L., Bastaits, K., \& Mortelmans, D. (2013). State-ofthe-art report. Effects of family forms and dynamics on children's well-being and life chances: Literature review. Families and Societies Working Paper Series No. 4.

Brickman, P., \& Campbell, D. T. (1971). Hedonic relativism and planning the good society. In M. H. Appley (Ed.), Adaptation-level theory (pp. 287-305). New York, NY: Academic Press.

Carlson, M. J., \& Berger, L. M. (2013). What kids get from parents: Packages of parental involvement across complex family forms. Social Service Review, 87, 213-249.

Carlson, M. J., \& Furstenberg, F. F. (2006). The prevalence and correlates of multipartnered fertility among urban U.S. parents. Journal of Marriage and Family, 68, 718-732.

Cherlin, A. J. (1978). Remarriage as an incomplete institution. American Journal of Sociology, 84, 634-650.

Cherlin, A. J. (2004). The deinstitutionalization of American marriage. Journal of Marriage and Family, 66, 848-861.

Clark, A. E. (2018). Four decades of the economics of happiness: Where next? Review of Income and Wealth, 2, 245-269.

Coleman, M., Ganong, L. H., \& Fine, M. (2000). Reinvestigating remarriage: Another decade of progress. Journal of Marriage and Family, 62, 1288-1307.

de Leeuw, E. D., \& de Heer, W. (2002). Trends in household survey nonresponse: A longitudinal and international comparison. In R. M. Groves, D. A. Dillman, J. L. Eltinge, \& R. J. A. Little (Eds.), Survey nonresponse (pp. 41-54). New York, NY: Wiley.

Di Leonardo, M. (1987). The female world of cards and holidays: Women, families, and the work of kinship. Signs, 12, 440-453.

Diener, E., \& Biswas-Diener, R. (2002). Will money increase subjective well-being? Social Indicators Research, 57, 119-169.

Diener, E., Emmons, R., Larsen, J., \& Griffin, S. (1985). The satisfaction with life scale. Journal of Personality Assessment, 49, 71-75.

Diener, E., Suh, E. M., Lucas, R. E., \& Smith, H. L. (1999). Subjective well-being: Three decades of progress. Psychological Bulletin, 125, 276-302.

Doodson, L. J. (2014). Understanding the factors related to stepmother anxiety: A qualitative approach. Journal of Divorce and Remarriage, 55, 645-667.

Doodson, L. J., \& Davies, A. P. C. (2014). Different challenges, different well-being: A comparison of psychological well-being across stepmothers and biological mothers and across four categories of stepmothers. Journal of Divorce and Remarriage, 55, 49-63.

Dush, C. M. K., \& Amato, P. R. (2005). Consequences of relationship status and quality for subjective wellbeing. Journal of Social and Personal Relationships, 22, 607-627.

Evenhouse, E., \& Reilly, S. (2004). A sibling study of stepchild well-being. The Journal of Human Resources, 39, 248-276.

Evenson, R. J., \& Simon, R. W. (2005). Clarifying the relationship between parenthood and depression. Journal of Health and Social Behavior, 46, 341-358.

Fine, M. A. (1986). Perceptions of stepparents: Variation in stereotypes as a function of current family structure. Journal of Marriage and the Family, 48, 537-543.

Fomby, P. (2018). Motherhood in complex families. Journal of Family Issues, 39, 245-270.

Gähler, M., \& Palmtag, E.-L. (2015). Parental divorce, psychological well-being and educational attainment: Changed experience, unchanged effect among Swedes born 1892-1991. Social Indicators Research, 123, 601-623.

Gratz, M. (2017). Does separation really lead fathers and mothers to be less involved in their children's lives? European Sociological Review, 33, 551-562.

Hagestad, G. O. (1986). The family: Women and grandparents as kinkeepers. In A. Pifer \& D. L. Bronte (Eds.), Our aging society: Paradox and promise (pp. 141-160). New York: Norton. 
Hank, K., \& Wagner, M. (2013). Parenthood, marital status, and well-being in later life: Evidence from SHARE. Social Indicators Research, 114, 639-653.

Hofferth, S. L., \& Anderson, K. G. (2003). Are all dads equal? Biologiy versus marriage as a basis for parental investment. Journal of Marriage and the Family, 65, 213-232.

Kalmijn, M. (2007). Gender differences in the effects of divorce, widowhood and remarriage on intergenerational support: Does marriage protect fathers? Social Forces, 85, 1079-1104.

Kalmijn, M., Ivanova, K., van Gaalen, R., de Leeuw, S. G., van Houdt, K., van Spijker, F., et al. (2018). A multi-actor study of adult children and their parents in complex families: Design and content of the OKiN survey. European Sociological Review, 34(4), 452-470.

Lappegård, T., \& Rønsen, M. (2013). Socioeconomic differences in multipartner fertility among Norwegian men. Demography, 50, 1135-1153.

Larsen, R. J. (2000). Toward a science of mood regulation. Psychological Inquiry, 11, 129-141.

Lykken, D., \& Tellegen, A. (1996). Happiness is a stochastic phenomenon. Psychological Science, 7, 186-189.

Lyngstad, T. H., \& Jalovaara, M. (2010). A review of the antecedents of union dissolution. Demographic Research, 23, 257-291.

Myrskylä, M., \& Margolis, R. (2014). Happiness: Before and after the kids. Demograhy, 51, 1843-1866.

Pace, G. T., \& Shafer, K. (2015). Parenting and depression: Differences across parental roles. Journal of Family Issues, 36, 1001-1021.

Pavot, W., \& Diener, E. (2009). Review of the satisfaction with life scale. In E. Diener (Ed.), Assessing wellbeing (pp. 101-117). Berlin: Springer.

Pudrovska, T. (2009). Parenthood, stress, and mental health in late midlife and early old age. International Journal of Aging and Human Development, 68, 127-147.

Roberts, B. W., Kuncel, N. R., Shiner, R., Caspi, A., \& Goldberg, L. R. (2007). The power of personality: The comparative validity of personality traits, socioeconomic status, and cognitive ability for predicting important life outcomes. Perspectives on Psychological Science, 2, 313-345.

Rosenthal, C. J. (1985). Kinkeeping in the familial division of labor. Journal of Marriage and Family, 47, 965-974.

Sanner, C., \& Coleman, M. (2017). (Re)constructing family images: Stepmotherhood before biological motherhood. Journal of Marriage and Family, 79, 1462-1477.

Shafer, K., \& Pace, G. T. (2015). Gender differences in depression across parental roles. Social Work, 60, 115-125.

Shapiro, D. N., \& Stewart, A. J. (2011). Parenting stress, perceived child regard, and depressive symptoms among stepmothers and biological mothers. Family Relations, 60, 533-544.

Skinner, K. B., Bahr, S. J., Crane, D. R., \& Call, V. R. A. (2002). Cohabitation, marriage, and remarriage: A comparison of relationship quality over time. Journal of Family Issues, 23, 74-90.

Stewart, S. D. (2005). Boundary ambiguity in stepfamilies. Journal of Family Issues, 26, 1002-1029.

Stewart, S. D. (2007). Brave new stepfamilies: Diverse paths toward stepfamily living. Thousand Oaks, CA: Sage Publications Inc.

Sweeney, M. M. (2010). Remarriage and stepfamilies: Strategic sites for family scholarship in the 21st century. Journal of Marriage and Family, 72, 667-684.

Thomson, E. (2014). Family complexity in Europe. The ANNALS of the American Academy of Political and Social Science, 654(1), 245-258.

Umberson, D., Pudrovska, T., \& Reczek, C. (2010). Parenthood, childlessness, and well-being: A life course perspective. Journal of Marriage and Family, 72(3), 612-629.

Ward, R. A., Spitze, G., \& Deane, G. (2009). The more the merrier? Multiple parent-adult child relations. Journal of Marriage and Family, 71, 161-173.

Weaver, S. E., \& Coleman, M. (2005). A mothering but not a mother role: A grounded theory study of the nonresidential stepmother role. Journal of Social and Personal Relationships, 22(4), 477-497.

Weaver, S. E., \& Coleman, M. (2010). Caught in the middle: Mothers in stepfamilies. Journal of Social and Personal Relationships, 27(3), 305-326.

Wiemers, E. E., Seltzer, J. A., Schoeni, R. F., Hotz, V. J., \& Bianchi, S. M. (2018). Stepfamily structure and transfers between generations in U.S. families. Demograhy. https://doi.org/10.1007/s13524-018-0740-1.

Yakovlev, P., \& Leguizamon, S. (2012). Ignorance is not bliss: On the role of education in subjective wellbeing. The Journal of Socio-Economics, 41, 806-815.

Publisher's Note Springer Nature remains neutral with regard to jurisdictional claims in published maps and institutional affiliations. 